\title{
The Concept of Emotional Intelligence - A Neglected Grey Area in Medical Curriculum
}

\author{
Neethu George ${ }^{1}$, Rock Britto Dharmaraj ${ }^{2}$, Nawin Jai Vignesh ${ }^{3}$, \\ Gokulapriya Baskaran ${ }^{4}$, Getha Marimuthu ${ }^{5}$, Gokulan Kuppuswamy ${ }^{6}$ \\ 1, 2, 3, 4,5, 6 Department of Community Medicine, Dhanalakshmi Srinivasan \\ Medical College Hospital, Perambalur, Tamilnadu India.
}

Emotional intelligence (EI) is the mixture of intellect and emotions. A highly emotional intelligent person showcases the ability to control, understand and being in other's shoes during the time of difficulties. The EI concept is extremely relevant in health care settings. The concept takes in the art of self-awareness, self-regulation, motivation, empathy, and social skills. These concepts in one way or the other help in rearing, mentoring, and reaching the heights of professionalism among medical students. The health care workers particularly doctors needed to be emotionally intelligent and should have maximum of it for effective outcomes and patient satisfaction. The current situation mandates the medical curriculum to have more of emotionally intelligent medical professionals than those with high intelligence quotient. The recent rise of dispute in health care field may be due to the reduction in emotional intelligence which triggers unhealthy recognition of emotions towards patients and bystanders. The need for the current digital and restricted mindset generation is to impart more of values and thus control and regulate one's own emotions. The study showcases various components, effects, and importance of emotional intelligence and also reviews few studies done on the topic with a special note on its importance in the current situation of Covid pandemic.

Emotional intelligence or emotional quotient (EQ) is the capability of a person to feel, recognize their emotions and emotions of other people. Intelligence quotient (IQ) alone is not enough, as a doctor's emotional intelligence is needed at many places. Emotional intelligence is a vast topic and has great impact on every person's life. People with emotional intelligence can achieve great things in life. Researchers have revealed that our success at work or in life, rest on emotional intelligence at 80 $\%$ and only $20 \%$ is of intellect. The intelligence is not only meant for success but also to earn trust and support from peers or the public. By having emotional intelligence, an individual can cope up with stress. Emotional intelligence makes a person to think of the positive outcomes during difficult situation. A person with high emotional intelligence will have less level of stress. Medical education is very hectic and leaves no time relax. Health care is the most stressful environment and it has many challenges. Emotional intelligence helps to manage our emotions and brings positive outcomes in critical situations. Emotional intelligence has a role in acknowledging one's own emotion and helps to act them between expected and unexpected situation. ${ }^{1,2}$

Self-awareness is important to all of us because it helps us to find our strength and weakness. Then automatically we must concentrate on these weaknesses and improve them up. Sometimes we overreact and under react at some point of time. So, self-regulation helps us to regulate ourselves during those over and under emotive stages. People with high emotional intelligence tend to be highly motivated, which makes them more resilient and optimistic. People with empathy are better in connecting with peoples. Sympathy alone is not enough. Empathy helps us to understand others, it can be patients, co-worker and family. Automatically one who is able to understand other feelings, emotions and felt empathy about others can easily able to socialize with others which is key thing needed for doctor. . $^{3,4}$
Corresponding Author: Dr. Neethu George, Assistant Professor, Department of Community Medicine, Dhanalakshmi Srinivasan Medical College Hospital, Perambalur - 621212, Tamilnadu,India.

E-mail: neethumampuzha@gmail.com

DOI: $10.14260 /$ jemds/2021/700

How to Cite This Article:

George N, Dharmaraj RB, Vignesh NJ, et al. The concept of emotional intelligence - A neglected grey area in medical curriculum. J Evolution Med Dent Sci 2021;10(38): 3457-3461 DOI:

10.14260/jemds/2021/700

Submission 07-07-2021,

Peer Review 31-08-2021,

Acceptance 06-09-2021,

Published 20-09-2021.

Copyright (C) 2021 Neethu George et al. This is an open access article distributed under Creative Commons Attribution License [Attribution 4.0 International (CC BY 4.0)] 


\author{
Positive Emotions of Emotional Intelligence \\ - Empathy \\ - Trust \\ - Comfort \\ - Rapport \\ - Satisfaction \\ - Patience
}

The students identified several positive influences of physician's emotional intelligence within the practice of medicine. The doctors felt that emotional intelligence will establish a rapport with the patient and provide a comfortable environment and emotional support. Emotional support is also an expression of empathy or relating to a patient as one's own loved ones. 5

\section{Negative Effects of Emotional Intelligence \\ - Communicates incompetence \\ - $\quad$ Lack of confidence \\ - Breach into patient's private space \\ - Loss of objectivity \\ - Instability \\ - Impair efficiency \\ - Undue paternalism}

The students felt that the doctor's emotional attachment with the patients is a major disadvantage and involving with a patient can lead to lack of confidence and loss of objectivity. It also leads to loss of efficiency of clinical care. The downside of being 'very emotionally intelligent' is that high EQ is appreciable, but the fact is that people with high EQ are calm, adjustable, soft, won't be stubborn, creative less due to satisfying all. So, once these type of people with high EQ become decision making authority like CEO, chief surgeon or head of hospital, they may fail to take firm decisions or procedures or new medical procedures because their higher EQ wish to satisfy all others and cautious. There could be lack of authoritative while high EQ people are at peak of hospital because of satisfying all. This shows the negative side of high EQ. 6

Importance of Emotional Intelligence

Emotional intelligence helps to understand emotional responses and it makes the person stronger. A person with high emotional intelligence can work better with others, thus leading to a successful business. Emotional intelligence helps to understand our own feelings and others. It helps to control and express our emotion, thus creating positive outcome. Emotional intelligence is a steppingstone through success. Emotional intelligence training in medical students helps them in managing the emotional circumstances in critical situation. EQ is very crucial skill that must be present with healthcare workers. It helps them to manage their own emotions and to understand others (patients \& co-workers) emotions and act. 2,7

\section{Application of Emotional Intelligence}

The person who has emotional intelligence will have successful career, good relationship, best leadership skills. Emotional intelligence is very useful for team leader to communicate with their team members effectively and brings best outcomes and hopefully bring successful business. Same will be applicable for medical practitioners to have effective doctor patient rapport. Emotional intelligence is useful for effective decision making, stress management, to handle exhausting work life in operation theatres, and to have good rapport with co medical and paramedical workers. These all will bring successful career.

Being optimistic is an important application of emotional intelligence. Emotional intelligence does not leave the person to step away while having argument, it helps to manage the situation and win the argument. Through emotional intelligence, a person can create good rapport and leave the employees satisfied. Emotional intelligence makes sense that late night meetings will affect your time with the family. Emotional intelligence acts to correct the issues rather than avoiding it. It makes us to accept our responsibilities making us compassionate when dealing with employer's personal problem which might be affecting their work. ${ }^{8-12}$

\section{Studies Done in the Topic among Medical Students}

Emotional intelligence of medical students doing their Masters in Delhi is measured with many variables [gender, age, shift timing, year of study, working hours per week, night shift hours, history of trauma]. It has been found that the emotional intelligence increases with age and experience.

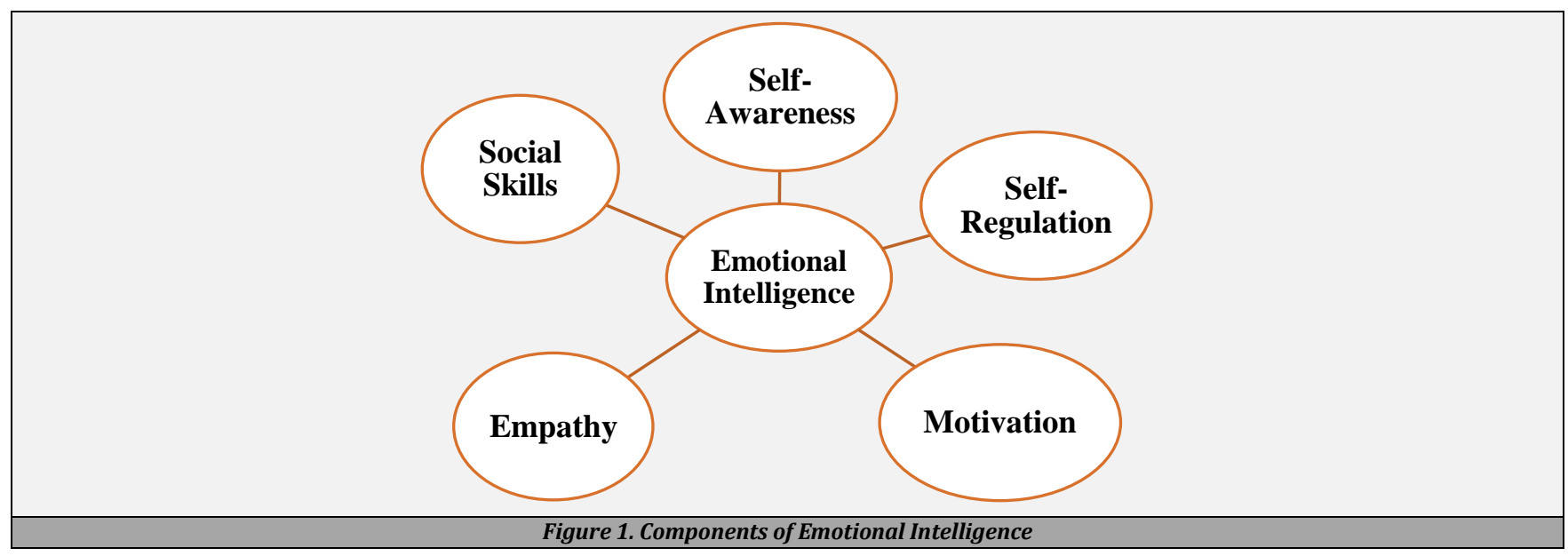


And at the same time, emotional intelligence is negatively affected by factors like workload, having night duties, and having emergency duties. However, findings show that emotional quotient is not affected by factors like gender, religion, choice of specialty and place of resident. ${ }^{13}$ Studies on emotional intelligence among medical students in Chennai found that students who went to government schools for high school education had greater emotional intelligence than students from private schools. Also, women were more emotionally intelligent than men.

Study on emotional intelligence of medical school students studying at London medical school - There was variation of 9.2 $\%$ in age, sex, and ethnicity and $7 \%$ of variance was explained by the stage of study. Final year student's score was higher than first 2-year students which shows EQ increase with the stage of the study. ${ }^{15}$ Study conducted among students in different medical sciences (medical school, paramedical school, school of health, nursing school, midwifery school, dentistry school) assesses prevalence and predictive of internet addiction and its relationship with EI. The result showed that internet addiction and emotional intelligence had an inverse and significant relationship among medical students. The study implies that we should take an effective move to improve and increase the student's emotions by providing special classes and workshops to avoid internet addiction. ${ }^{16}$

The study conducted among Iranian medical students to assess the association between emotional intelligence and learning strategy showed no significant association between EI and learning strategies in participants, but emotional intelligence components showed a positive role in learning strategies like self-efficacy, self-regulation, time, rehearsal, cognitive, environment management, peer learning and help seeking. The study concludes that strengthening of emotional intelligence facilitates learning. ${ }^{17}$ The study aimed to investigate emotional intelligence among students university of Ahvaz. The study results showed that emotional intelligence have no significant relationship with students age, marital status, degree, job, sex. Also, emotional intelligence and its importance in promotion of health care and academic performance should be given more attention in the medical field. ${ }^{18}$

Emotional intelligence has been shown to influence educational performance and perceived stress. This study explored the link between emotional intelligence, perceived stress, and educational performance among first year medical students. The result showed that neither perceived stress nor emotional intelligence were associated with educational performance. But those subjects with higher emotional intelligence perceived less stress. Therefore, it would be practical to coach medical students to spread their emotional intelligence to encourage their well-being. ${ }^{19} \mathrm{~A}$ cross-sectional study among 571 medical students to assess students' EI, and its associated factors showed a declining pattern of EI, personal competence and social competence level as medical training progresses. Male considerably had a better EI and personal competency levels than female medical students. ${ }^{20}$

In a study which aimed to assess the association of EI with academic accomplishment and general health among medical students. A positive relationship between emotional intelligence, academic achievement, and general health was noted in the study. ${ }^{21} \mathrm{~A}$ study was conducted to assess the predictors of emotional intelligence and its relationship with tutorial performance, leadership capability, self-efficacy and the perceived stress between medical students at kingdom of Saudi Arabia. The variables associated with high EI were gender (female), increasing age, and being non-smoker. EI was positively associated to higher tutorial performance, leadership capability and self-efficacy. It was negatively related to perceived stress. ${ }^{22}$

Another study was done to assess EI and its associated factors and to work out any association between EI and educational performance among final year dental students in Bengaluru, India. EI was considerably larger in females than males. Gender, sleep, meeting friends, work up, recreational activities, and educational performance were significantly related to EI and was positively linked with educational performance. ${ }^{23}$ Another study showed addition of extracurricular activities like dance and sports along with academics may improve the self-confidence and increased awareness about one's own emotions, leading to raised EI ${ }^{24}$ In a study done to explore the link between EI, perceived stress and educational performance and associated factors among medical undergraduates in Sri Lanka. The result showed that females had higher mean EI scores. A positive relationship was found between the EI score and the number of extracurricular activities. Those who were satisfied concerning their choice to study medicine, and who were planning to do postgraduate studies had significantly higher EI scores and lower stress scores. ${ }^{25}$

\section{The Need for Emotional Intelligence during Pandemics}

At times, national or international level crisis would develop which would topple all the normal life situations of the public. The need of change in approach towards the components of EI needed at the time of crisis in the medical filed which is shown in figure below.

\section{Recommendation of Emotional Intelligence in Medicine}

Emotional intelligence emphasize that medical education includes communication and empathy. Ethical value system, knowledge and interpersonal skills are the key components in medical system. Therefore, acquiring knowledge and skills alone does not make a doctor, but also ethics and interpersonal skills. Emotional intelligence is a stepping stone to create doctor patient relationship in future. Emotional intelligence training is mandatory for every medical student for the best patient doctor relationship. Face to face discussion, role play scenarios and dramas in emotionally trying situations will be helpful to understand about emotional intelligence. Training for medical students in view of emotional intelligence provide emotional skills (e.g., Perceiving, understanding, using, and managing emotions) will be improved through medical coaching. Emotional intelligence programs should be established ways in which to implement, monitor, and appraise the observe. The medical curriculum has some glimpse already in terms with emotional intelligence which is the "sociology chapter" in community medicine, but the portion is not given apt importance. 


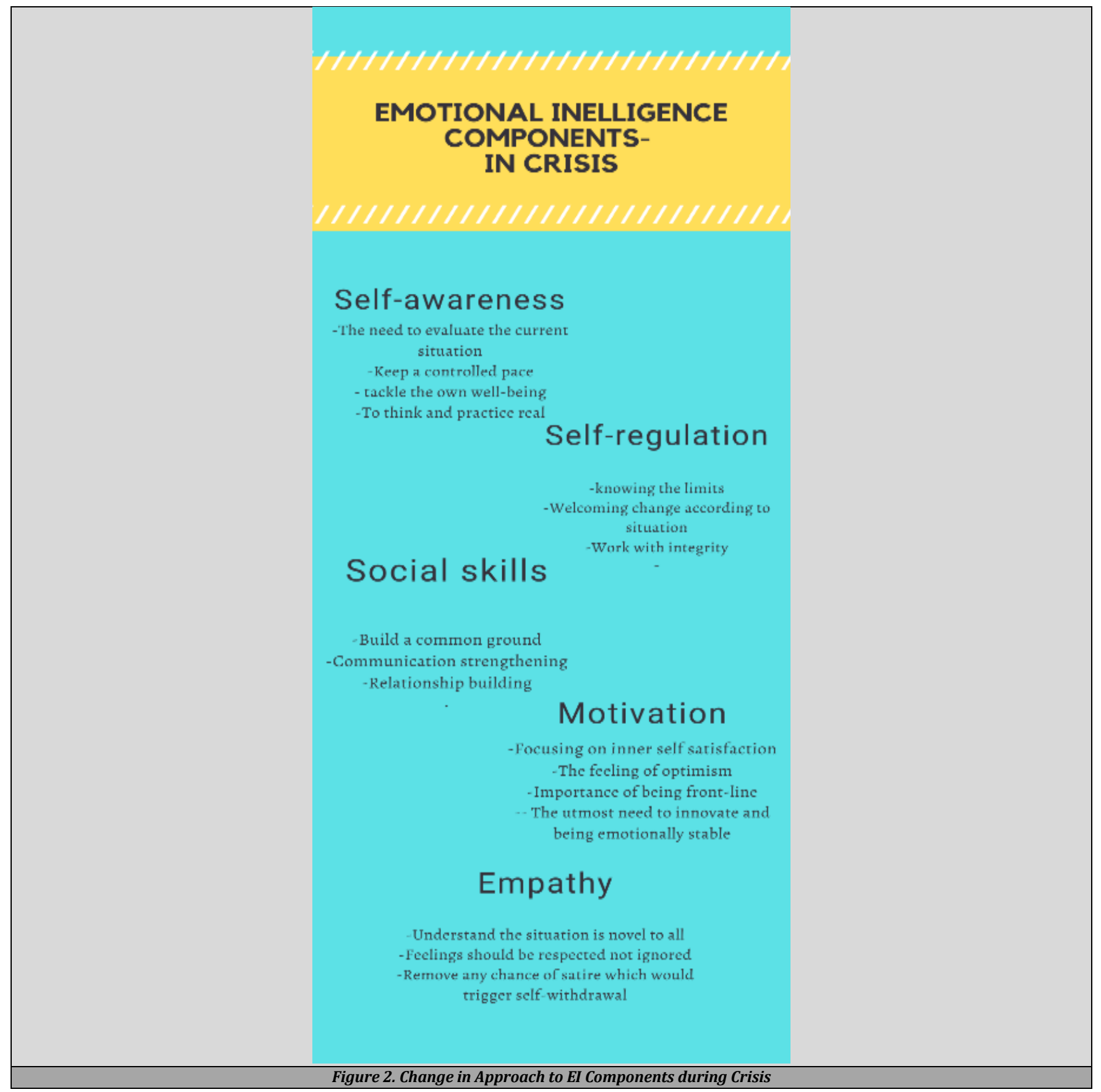

\section{CONCLUSIONS}

Emotional intelligence may also be thought of a key driver of success and lead. Emotional intelligence-based education can also contribute to the teaching of expertness and communication skills. It may be unfortunate that, traditionally, such nice stress has been placed on intelligence quotient and technical ability, whereas scant attention has been paid to emotional intelligence, now maybe the time for educators, still as clinicians themselves, to change pre- and postgraduate curriculam and coaching accordingly. ${ }^{10,12}$

Financial or other competing interests: None.

Disclosure forms provided by the authors are available with the full text of this article at jemds.com.

\section{REFERENCES}

[1] Cotruş A, Stanciu C, Bulborea AA. EQ vs. IQ Which is most important in the success or failure of a student? Procedia - Soc Behav Sci 2012;46:5211-13.

[2] Serrat 0. Understanding and developing emotional intelligence BT - knowledge solutions: tools, methods and approaches to drive organizational performance. $1^{\text {st }}$ edn. Springer Singapore 2017: p. 329-39.

[3] Goleman D. Emotional intelligence: issues in paradigm building. In: Cherniss C, Goleman D, eds. The Emotionally Intelligence Workplace. San Francisco: Jossey Bass Company, 2001;13:26.

[4] Goleman D. Emotional intelligence: Why it can matter more than IQ. Bantam 2012. 
[5] Modi JN, Gupta P, Singh T. Competency-based medical education, entrustment and assessment. Indian Pediatr 2015;52(5):413-20.

[6] Mayer JD, Roberts RD, Barsade SG. Human abilities: emotional intelligence. Annu Rev Psychol 2008;59:50736.

[7] Gendron B. Why emotional capital matters in education and in labour? Toward an optimal exploitation of human capital and knowledge management. In: Les Cahiers de la Maison des Sciences Economiques. Paris: Université Panthéon-Sorbonne, 2004;113:35.

[8] Amundson SJ. The impact of relational norms on the effectiveness of health and human service teams. Health Care Manag (Frederick) 2005;24(3):216-24.

[9] Dinapoli R. Using dramatic role-play to develop emotional aptitude. Int J English Stud 2009;9(2):97-110.

[10] Johnson DR. Emotional intelligence as a crucial component to medical education. Int J Med Educ 2015;6:179-83.

[11] Kirk LM. Professionalism in medicine: definitions and considerations for teaching. Proc (Baylor Univ Med Cent) 2007;20(1):13-6.

[12] Guseh SH, Chen XP, Johnson NR. Can enriching emotional intelligence improve medical students' proactivity and adaptability during OB/GYN clerkships? Int J Med Educ 2015;6:208-12.

[13] Ravikumar R, Rajoura OP, Sharma R, et al. A Study of emotional intelligence among postgraduate medical students in Delhi. Cureus 2017;9(1):e989.

[14] Sundararajan S, Gopichandran V. Emotional intelligence among medical students: a mixed methods study from Chennai, India. BMC Med Educ 2018;18(1):97.

[15] Todres M, Tsimtsiou Z, Stephenson A, et al. The emotional intelligence of medical students: an exploratory crosssectional study. Med Teach 2010;32(1):e42-8.

[16] Yekefallah L, Dehghankar L, Razaghpoor A, et al. The prevalence and predictive factors of internet addiction and its relationship with emotional intelligence among medical students. Soc Heal Behav 2019;2(4):145-50.

[17] Sheikhbardsiri H, Sheikhasadi H, Mahani SA, et al. Emotional intelligence and learning strategies of postgraduate students at Kerman University of Medical Sciences in the southeast of Iran. J Educ Health Promot 2020;9:66.

[18] Ghaderi M, Nasiri M, Zakeri Y, et al. Evaluation of emotional intelligence in Ahvaz Universities Students in 2014. Journal of Rafsanjan University of Medical Sciences 2015;14(5):379-92.

[19] Gupta R, Singh N, Kumar R. Longitudinal predictive validity of emotional intelligence on first year medical students perceived stress. BMC Med Educ 2017;17(1):139.

[20] Khraisat A, Rahim AFA, Yusoff MSB. Emotional intelligence of USM medical students. Educ Med J 2015;7(4):e28-e37.

[21] Gorgich CEA, Barfroshan S, Ghoreishi G, et al. The association of self - assessed emotional intelligence with academic achievement and general health among students of medical sciences. Glob J Health Sci 2016;8(12):27-31.

[22] Ibrahim NK, Algethmi WA, Binshihon SM, et al. Predictors and correlations of emotional intelligence among medical students at King Abdulaziz University, Jeddah. Pakistan J Med Sci 2017;33(5):1080-5.

[23] Kumar A, Puranik MP, Sowmya KR. Association between dental students' emotional intelligence and academic performance: a study at six dental colleges in India. J Dent Educ 2016;80(5):526-32.

[24] George N, Britto RD, George M, et al. Dance, sports or academics: which monopolize students emotional quotient. Int J Res Med Sci 2018;6(11):3714-20.

[25] Ranasinghe P, Wathurapatha WS, Mathangasinghe Y, et al. Emotional intelligence, perceived stress and academic performance of Sri Lankan medical undergraduates. BMC Med Educ 2017;17(1):41. 